\title{
Analysis of The Economic Operation of Micro Grid Considering Forecasting Error
}

\author{
Yuanyuan Rong ${ }^{1, \mathrm{a}}$, Xiaohe $\mathrm{Liu}^{1, \mathrm{~b}}$, Rong Ju ${ }^{1}$, Yong $\mathrm{Ju}^{1}$, Xinying $\mathrm{Ji}^{1}$ \\ ${ }^{1}$ Nanjing Normal University, Nanjing, Jiangsu, China \\ aryynnu@163.com \\ blxh163nnu@163.com
}

Keywords: Micro grid; Forecasting error; PSO; Economic operation

Abstract. Energy optimization plan is necessary to ensure the safety, the stability and the economy of the power dispatch. The most common method of energy optimization plan is the day-ahead dynamic economic dispatch by the short-term forecast. However, due to the forecasting error of the distributed generation, the plan is often not the best. In order to reduce the influence of the forecasting error on the economic dispatch, $t$ location-scale function is used to quantify the forecasting error, and adjust the economic dispatch plan to get more actual economic operation plan.

\section{Introduction}

At present, the research on the economic operation of micro grid gets people's attention. [1] set up the dynamic economic dispatch plan, compared with other dispatch strategies under scenarios with different depreciation cost and power rates. [2] set up the multi-objective optimal operation model of the economy and environmental protection, and used the improved multi-objective particle swarm optimization (PSO) algorithm to solve it. But the dispatch plans of [1] and [2] are just for the day-ahead dynamic economic dispatch, without considering the forecasting error's influence on the economic operation. In [3] and [4], the normal distribution function is introduced to quantify the forecasting error, but can't accurately reflect the forecasting error.

To solve above problems, this paper uses t location-scale function to quantify the distributed generation forecasting error, and adds the forecasting error in economic dispatch plan to complete the correction. It uses the particle swarm optimization algorithm to solve the objective function, and gets more actual economic operation plan.

\section{The estimate of forecasting error}

A large number of literature describe the forecasting error in normal distribution [3, 4], but much measured data shows that the difference between the normal distribution function and the frequency distribution histogram is very large. In comparison, $t$ location-scale function can better match the frequency distribution histogram [5].

The $t$ location-scale is a kind of $t$ distribution containing the scale and location parameters. The probability density function of $t$ distribution is expressed as (1). The probability density function of $t$ location-scale distribution is expressed as (2) [5].

$$
\begin{aligned}
& f(x)=\frac{\Gamma(v+1 / 2)}{\sqrt{v \pi} \Gamma(v / 2)}\left(1+\frac{x^{2}}{v}\right)^{-(v+1) / 2} \\
& f(x)=\frac{\Gamma(v+1 / 2)}{\sigma \sqrt{v \pi} \Gamma(v / 2)}\left[\frac{v+(x-\mu / \sigma)^{2}}{v}\right]^{-v+1 / 2} .
\end{aligned}
$$

In (1) and (2), $v$ is the shape parameter; $\mu$ is the location parameter; $\sigma$ is the scale parameter. 


\section{Correction of the day-ahead economic dispatch}

The power of the wind turbine and the photovoltaic is affected by the climate and the temperature with strong randomness and volatility, so the wind turbine and the photovoltaic belong to the uncontrolled power supply in micro grid. Gas turbine and diesel generators can stable output power, belong to the controllable power supply. See wind power and solar power as a power supply load to establish the formula of the net load [6], shown as

$$
P_{n e t}=\sum_{i \in S_{L}} P_{L i}-\sum_{i \in S_{W T}} P_{W T i}-\sum_{i \in S_{P V}} P_{P V i}
$$

In (3), $P_{\text {net }}$ is the net load $(\mathrm{kW}) ; P_{L i}$ is the load $(\mathrm{kW}) ; P_{W T i}$ is the forecasting power of the wind turbine $(\mathrm{kW}) ; P_{P V i}$ is the forecasting power of the photovoltaic; $S_{L}$ is the array of the load; $S_{W T}$ is the array of the wind turbine; $S_{P V}$ is the array of the photovoltaic.

Considering the forecasting error in (3), get the corrected formula, shown as

$$
P_{n e t}^{\prime}=\sum_{i \in S_{L}} P_{L i}-\sum_{i \in S_{W T}} P_{W T i}-\sum_{i \in S_{P V}} P_{P V i}-\sum_{i \in S_{W T} P V} \Delta P_{W T_{-} P V i} .
$$

In (4), $S_{W T_{-} P V}$ is the total array of the wind turbine and the photovoltaic; $\Delta P_{W T_{-} P V i}$ is the power forecasting error of the wind turbine and the photovoltaic. When prediction slants big, the $\Delta P_{W T_{-} P V i}$ is positive, Otherwise it is negative.

\section{The model and the constraint condition}

The wind turbine. Different kinds of wind turbine have some differences in power output characteristic curve. The main models of the output power are the linear model, the quadratic model, the three power model, the exponential model and the Weibull distribution model [7]. Now widely used output power model is the quadratic model [2], which is expressed as

$$
P_{W T}=\left\{\begin{array}{ll}
0 & v<v_{c i}, v \geq v_{c o} \\
a v^{2}+b v+c & v_{c i} \leq v<v_{r} \\
P_{W T r} & v_{r} \leq v<v_{c o} .
\end{array} .\right.
$$

In (5), $P_{W T}$ is the output power of the wind turbine $(\mathrm{kW}) ; v$ is the wind speed $(\mathrm{m} / \mathrm{s}) ; v_{c i}$ is the cut-in wind speed $(\mathrm{m} / \mathrm{s}) ; v_{c o}$ is the cut-out wind speed $(\mathrm{m} / \mathrm{s}) ; a b$ and $c$ are the parameters of the wind turbine power curve; $P_{W T r}$ is the power rating of the wind turbine $(\mathrm{kW})$.

The photovoltaic cell. The output power of the photovoltaic cell has strong randomness, volatility and nonlinear properties, which is associated with light intensity and environment temperature [2], shown as

$$
P_{P V}=f_{P V} P_{S T C} G\left[1+k\left(T_{c}-T_{r}\right)\right] / G_{S T C} .
$$

In (6), $P_{P V}$ is the output power of the photovoltaic cell $(\mathrm{kW}) ; f_{P V}$ is the factor of the power decrease because of the dust and the snow on the surface of the photovoltaic cell, and usually takes $0.9 ; P_{S T C}$ is the maximum power under the standard test environment $\left(1 \mathrm{~kW} / \mathrm{m}^{2}, 25^{\circ} \mathrm{C}\right) ; G$ is the current actual light intensity $\left(\mathrm{kW} / \mathrm{m}^{2}\right) ; k$ is the power temperature factor; $T_{c}$ is the surface temperature of the photovoltaic cell at present $\left({ }^{\circ} \mathrm{C}\right) ; T_{r}$ is the surface temperature of the photovoltaic cell under the standard test environment, and usually takes $25^{\circ} \mathrm{C} ; G_{S T C}$ is the light intensity under the standard test environment, and usually takes $1 \mathrm{~kW} / \mathrm{m}^{2}$.

The micro gas turbine. The micro gas turbine converts heat into mechanical energy through the fuels such as natural gas and so on. The power generation cost of the micro gas turbine is expressed as

$$
C_{M T}=\frac{c_{\text {fuel }}}{L H V} \bullet \frac{P_{M T} \Delta t}{\eta_{M T}} .
$$


In (7), $C_{M T}$ is the power generation cost of the micro gas turbine (\$); $c_{f u e l}$ is the price of the fuel (\$); $L H V$ is the low heat value of the fuel, and the natural gas $L H V$ is $9.7 \mathrm{~kW} \cdot \mathrm{h} / \mathrm{m}^{3} ; P_{M T}$ is the output power of the micro gas turbine $(\mathrm{kW}) ; \Delta t$ is the operation time of the micro gas turbine $(\mathrm{h}) ; \eta_{M T}$ is the power generation efficiency of the micro gas turbine.

The fuel cell. The fuel cell has high resource efficiency, because it can directly convert chemical energy into electricity. The power generation cost model of the fuel cell is same as the micro gas turbine [2], shown as

$$
C_{F C}=\frac{c_{\text {fuel }}}{L H V} \bullet \frac{P_{F C} \Delta t}{\eta_{F C}}
$$

The main difference of the power generation cost between the fuel cell and the micro gas turbine is the power generation efficiency. The power generation efficiency of the fuel cell reduces with the increase of output power, while the micro gas turbine is on the contrary [8].

The diesel generator. The power generation cost of the diesel generator is mainly related to its active power, usually expressed in quadratic polynomial [2], shown as

$$
C_{D G}=a P_{D G}^{2}+b P_{D G}+c \text {. }
$$

In (9), $C_{D G}$ is the power generation cost of the diesel generator (\$); $P_{D G}$ is the output power of the diesel generator $(\mathrm{kW}) ; a b$ and $c$ are the parameters of the quadratic polynomial.

The objective function. This paper establishes the objective function of the operation cost under the islanded micro grid. There is no energy exchange between the micro grid and the distribution network, so don't need to consider the cost of buying or outputting electricity from the distribution network. The operation cost mainly includes the fuel cost of the distributed generation, the operation maintenance cost and the depreciation cost, shown as

$$
\min C=\sum_{t=1}^{T} \sum_{i=1}^{N}\left[C_{f u e l}(i, t)+C_{O M}(i, t)+C_{D E}(i, t)\right]
$$

In (10), $C$ is the total operation cost of a running cycle ( $\$$ ); $T$ is the periods of a running cycle; $N$ is the kinds of the distributed generation; $C_{f u e l}(i, t)$ reflects the fuel cost of the first $\underline{i}$ kind of the distributed generation in the first $\mathrm{t}$ period of a running cycle $(\$) ; C_{O M}(i, t)$ reflects operation maintenance cost of the first $i$ kind of the distributed generation in the first $t$ period of a running cycle $(\$) ; C_{D E}(i, t)$ reflects the depreciation cost of the first $\mathrm{i}$ kind of the distributed generation in the first $\mathrm{t}$ period of a running cycle $(\$)$.

The constraint condition. The most important constraint in the micro grid is the power balance, shown as

$$
P_{n e t}^{\prime}=\sum_{i \in S_{M T}} P_{M T i}+\sum_{i \in S_{F C}} P_{F C i}+\sum_{i \in S_{D G}} P_{D G i}+\sum_{i \in S_{B a t}} P_{B a t} .
$$

In (11), $P^{\prime}{ }_{n e t}$ is the net load shown as (4); $P_{M T}$ is the output power of the micro gas turbine (kW); $P_{F C}$ is the output power of the fuel cell $(\mathrm{kW}) ; P_{D G}$ is the output power of the diesel generator $(\mathrm{kW})$; $P_{B a t}$ is the charging or discharging power of the battery $(\mathrm{kW})$, and discharge is positive, while the charge is negative; $S_{M T}$ is the array of the micro gas turbine; $S_{F C}$ is the array of the fuel cell; $S_{D G}$ is the array of the diesel generator; $S_{B a t}$ is the array of the battery.

The constraint condition of the distributed generation's output power is expressed as

$$
P_{i \min } \leq P_{i} \leq P_{i \max } \text {. }
$$

In (12), $P_{i}$ is the output power of the first $\mathrm{i}$ kind of the distributed generation $(\mathrm{kW}) ; P_{\text {imin }}, P_{\text {imax }}$ is the minimum and maximum output power of the first $\mathrm{i}$ kind of the distributed generation $(\mathrm{kW})$.

The battery mainly considers the constraint condition of state of charge, shown as

$$
S O C_{\min } \leq S O C \leq S O C_{\max } .
$$


In (13), $S O C_{\min }, S O C_{\max }$ is the minimum and maximum state of charge.

\section{Model solution}

Optimization algorithm such as genetic algorithm and particle swarm optimization algorithm is widely used in economic operation of the micro power grid. Particle swarm optimization algorithm, imitating birds foraging process, solves solution easily, converges fast and has high precision. This paper, using particle swarm optimization algorithm, solves the objective function of the the operation cost, as shown in fig.1.

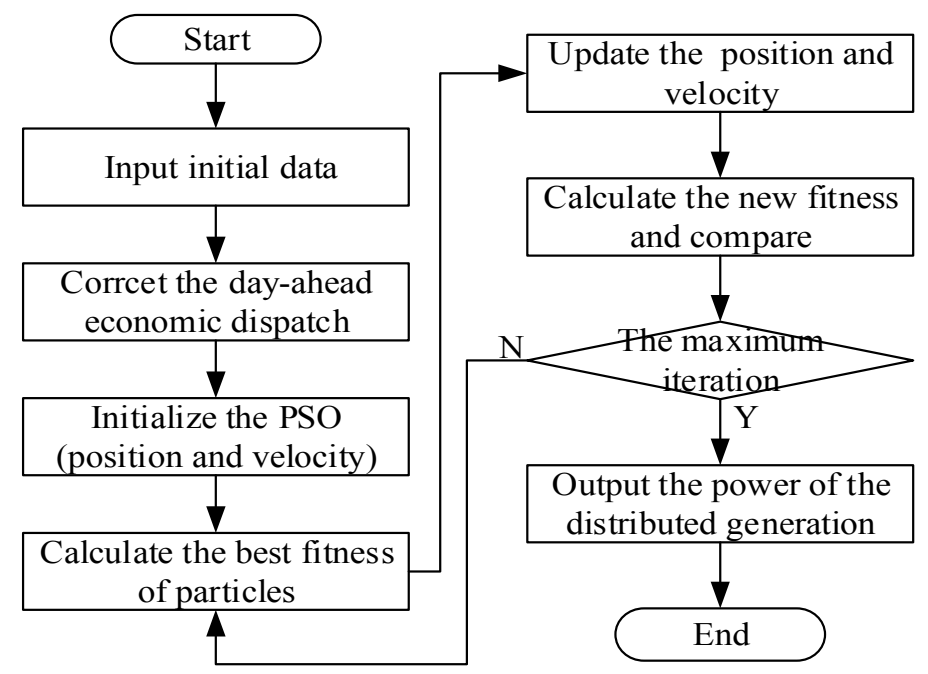

Fig.1 The flow chart of micro grid economic operation

\section{Example}

In this paper, the islanded micro grid includes the wind turbine, the photovoltaic cell, the micro gas turbine, the fuel cell and the diesel generator. One day as a scheduling cycle, is divided into 24 hours. The load power is $[68,63,60,77,92,93,101,97,109,122,139,142,141,127,120,124,144,146$, $148,142,121,90,86] \mathrm{kW}$. Fig. 3 is the forecasting power of the the wind turbine and the photovoltaic cell. The maximum and minimum output power of the micro gas turbine, the fuel cell and the diesel generator is $40 \mathrm{~kW}$ and $10 \mathrm{~kW}$. Battery capacity is $50 \mathrm{~kW} \cdot \mathrm{h}$, and the initial capacity is $25 \mathrm{~kW} \cdot \mathrm{h}$. The $S O C_{\min }$ is 0.1 , and $S O C_{\max }$ is 0.9 . The population size of particle swarm optimization is 30 , and the largest number of iterations is 500 . Figure 4 is the output power of the distributed generation.

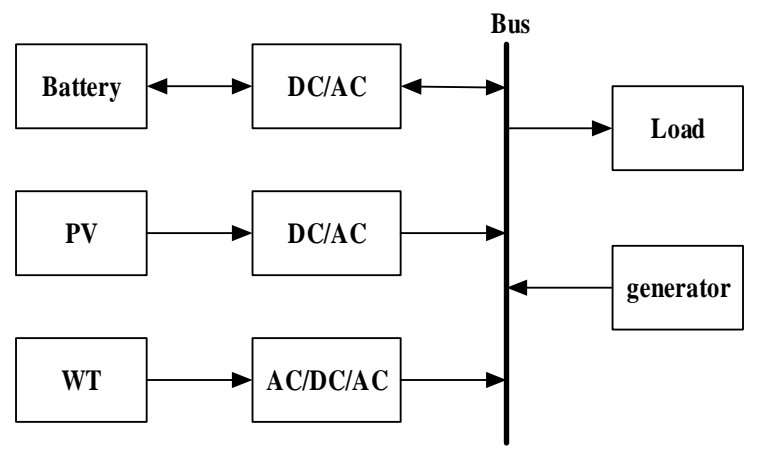

Fig.2 The micro grid structure

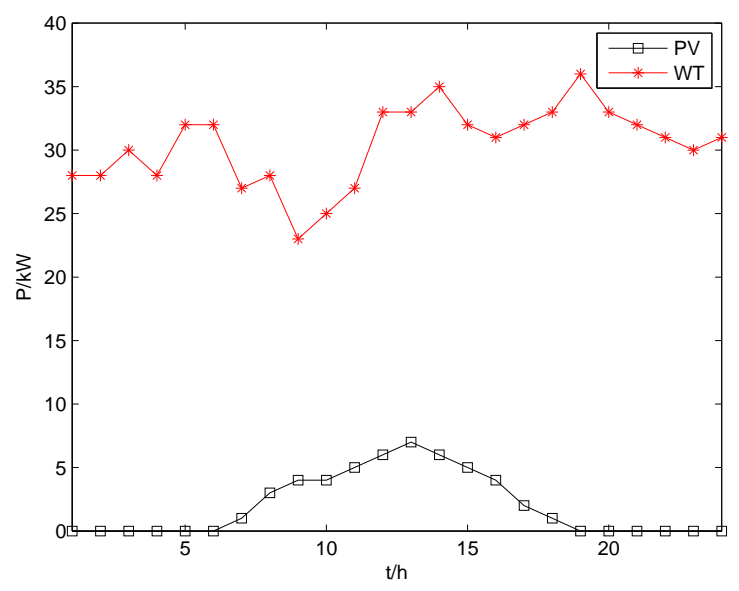

Fig.3 The forecasting power of the PV and WT 


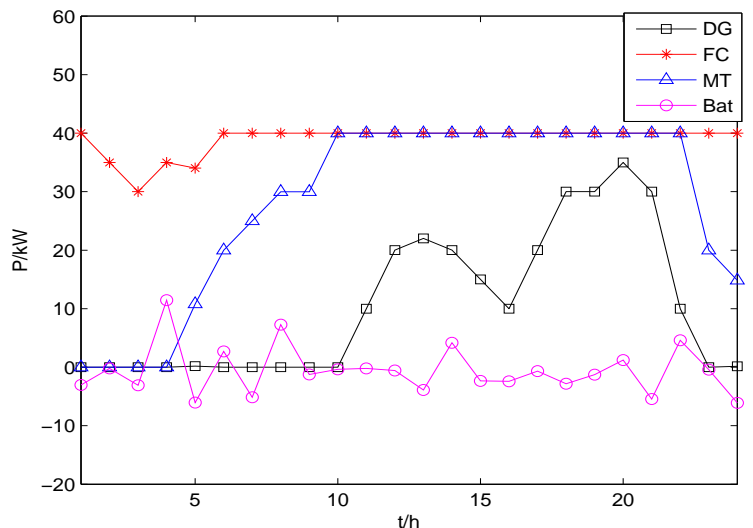

Fig.4 The output power of the distributed generation

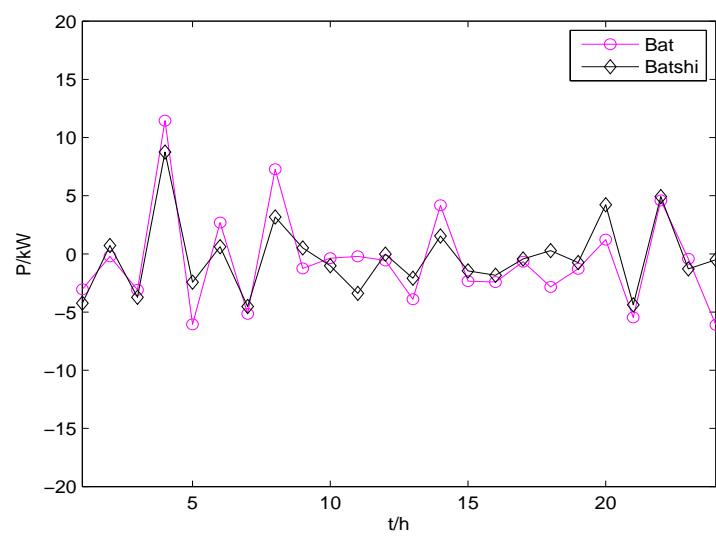

Fig. 5 The output power of the battery

In fig.4, when the output power of the wind turbine and the photovoltaic cell can't satisfy the load, the fuel cell firstly output the power, the micro gas turbine secondly, the diesel generator finally. The battery don't take part in the economic operation, and just balance the power change caused by the forecasting error of the wind turbine and the photovoltaic cell. Fig.5 is the forecasting and the actual output power of the battery. In a cycle, the actual adjustment of the battery is $77 \mathrm{~kW}$, while the forecasting adjustment is $57 \mathrm{~kW}$, so adding the forecasting error can effectively reduce the adjustment, in accordance with the actual situation even more.

\section{Conclusion}

This paper, to reduce the influence of the forecasting error on economic operation, uses $t$ location-scale function to quantify the forecasting error, and adds it into the day-ahead dynamic economic dispatch. The example reflects that considering the forecasting error can effectively reduce the adjustment.

\section{References}

[1] Wang Chenshan, Hong Bowen, Guo Li. Dispatch strategies of PV-Battery microgrid in different scenarios[J]. Power System Technology, 2013(7):1775-1782.

[2] Huang Min. Research of multi-objective optimal operation for a micro-grid based on improved particle swarm optimization[D]. Chongqing University, 2014.

[3] Li Pengmei, Zang Chuanzhi, Li Hepeng, etc. Energy stochastic optimization scheduling for micro-grid based on photovoltaic forecasting $[\mathrm{J}]$. Transducer and Microsystem Technologies, 2015(2):61-64.

[4] Sun Min, Dou Xiaobo, Shen Yang, etc. The study on daily economic dispatch of microgrid considering source load forecasting error[J]. Power Demand Side Management, 2014, 16(3):1-6.

[5] Lin Weixing, Wen Jinyu, Ai Xiaomeng, etc. Probability Density Function of Wind Power Variations[J]. Proceedings of the CSEE, 2012, 32(1):38-46.

[6] Jing Qiyun. Stand-alone microgrid coordination control strategy based on net load forecasting[J]. Journal of Mechanical \& Electrical Engineering, 2013, 30(10):1259-1263.

[7] Li Chong, Zheng Yuan, Zhu Dasheng, etc. A study on power output models of wind turbine[J]. Water Power, 2014, 40(8):123-125.

[8] Shi Qingjun. Research on optimal sizing and optimal energy management for microgrid[D]. Zhejiang University, 2012. 